\title{
CRESUS: A TOOL TO SUPPORT COLLABORATIVE REQUIREMENTS ELICITATION THROUGH ENHANCING SHARED UNDERSTANDING AND SIMULATION
}

\author{
Paul Stynes ${ }^{1}$, Owen Conlan ${ }^{2}$ and Declan O'Sullivan ${ }^{3}$ \\ ${ }^{1}$ School of Computing, National College or Ireland, Dublin, Ireland \\ ${ }^{2,3}$ School of Computer Science and Statistics, \\ Trinity College Dublin, Dublin 2, Ireland
}

\begin{abstract}
Communicating an organisation's requirements in a semantically consistent and understandable manner and then reflecting the potential impact of those requirements on the IT infrastructure presents a major challenge among stakeholders. Initial research findings indicate a desire among business executives for a tool that allows them to communicate organisational changes using natural language and a simulation of the IT infrastructure that supports those changes. Building on a detailed analysis and evaluation of these findings, the innovative CRESUS tool was designed and implemented. The purpose of this research was to investigate to what extent CRESUS both aids communication in the development of a shared understanding and supports collaborative requirements elicitation to bring about organisational, and associated IT infrastructural, change. This paper presents promising results that show how such a tool can facilitate collaborative requirements elicitation through increased communication around organisational change and the IT infrastructure.
\end{abstract}

\section{KEYWORDS}

Collaborative requirements elicitation, Shared Understanding, and Semantically enabled web services.

\section{INTRODUCTION}

Successfully understanding an organisation's requirements in such a manner that their impact on the IT infrastructure can be analysed and discussed, presents a major challenge [1-3] between the business executive, IT architect and other stakeholders. The most significant problem arises in communicating the requirements desired in a semantically consistent and understandable manner and then reflecting the potential impact of those requirements on the IT infrastructure.

Research indicates that there are numerous tools [4-7] that support requirements elicitation. However, none of them incorporate simulation as an elicitation technique to study the impact requirements will have on the organisational and associated IT infrastructure changes. Simulation models play an important role in displaying significant features and characteristics of a dynamic system, which one wishes to study [8]. One of the approaches Chandrasekaran et al [9] proposes 
is the creation of simulation models from web services. This approach provides a high fidelity between the simulation and real world. Moreover, it provides an ability to plug real web services into simulated entities, thus creating simulations that utilise as much 'real world' data as possible. An initial evaluation of a scenario-based prototype was conducted with ten business executives in higher education. The purpose of the evaluation was to examine the desire for a tool that allows business executives communicate about organisational and IT infrastructural changes [10]. The analysed data produce results that indicate a desire for such a tool with open comments such as "The idea seems to be very good, especially the natural language interface, which I particularly like", and "Good to specify objectives through the use of goals". Quantitative results reinforce the comments. They indicate that the majority of this small sample group (6 executives) like the approach of specifying their goals and rules in natural language. In addition, the majority (7 executives) liked the approach where the system automatically identifies a business process that may solve the executive's goal, and applies rules to services in the process. While this was only a limited survey the results indicate promise. The executives intuitively understood the approach being proposed. That is to augment the requirements gathering process with semantics that drives the formulation of organisational changes using controlled natural language. In addition, they also liked the simulation of the IT infrastructure that supports those changes. Moreover, they strongly indicated that they believed such an approach was desirable.

Building on the evaluation, CRESUS was designed and implemented as a collaborative requirements elicitation tool. The tool allows stakeholders communicate requirements guided by an ontological domain model, then validate the requirements, and finally create a simulation of the IT infrastructure that supports those requirements.

This research investigates to what extent CRESUS both aids communication in the development of a shared understanding and supports collaborative requirements elicitation to bring about organisational, and associated IT infrastructural, change.

The remainder of this paper describes the related work in section 2, then an outline of research, followed by architecture and implementation. Section 5 describes the evaluation, followed by limitations, and future work.

\section{RELATED WORK}

The elicitation or communication of requirements is recognised as a critical activity of software development [11]. The goal of which is to reach a shared understanding between all parties involved in the communication process. An increased amount of communication effort [12] is often required to overcome the gap in communicating the requirements desired in a semantically consistent and understandable manner and then reflecting the potential impact of those requirements on the IT infrastructure.

Effective communication has been difficult to achieve and is a recurring problem in the elicitation of requirements [13]. Macaulay [14] identifies communication as a key factor to the design of successful systems. Christal et al. [15] categorise the problems of requirements elicitation that relate to scope, understanding and volatility where communication features strongly in gaining an understanding. Coughlan et al. [16] conducted an analysis of effective communication in requirements elicitation. They discuss the user-centred (problem finding viewpoint that advocates an emergent and collaborative nature to requirements that emerge as part of on-going interactions and negotiations between participants. This problem finding approach involves spending more time communicating and developing relationships which has been linked to greater success in the determination of requirements [17]. Coughlan et al. [16] conclude with four recommendations for effective communication for an organization and its stakeholders in attempting to integrate 
technology namely, include users in the design; select an adequate mix of IT and business users who then interact on a cooperative basis; the incorporation of communication activities that relate to knowledge acquisition, knowledge negotiation and user acceptance; the use of elicitation techniques for mediating communication for the requirements of a system such as prototyping, questionnaires, brainstorming, scenarios, etc.

This research proposes to use simulation as an elicitation technique for creating the IT infrastructure. In this context, simulation has the potential to evolve into a prototype.

Tools that support requirements elicitation can be categorised as non web-based and web-based. Non web-based tools are VORDTool [18], FAES [5], AMORE [6], and JPreview [7]. The webbased tools are TeamWave [19] and WRET [20]. Web based tools support distributed collaborative requirements elicitation.

Current research on web-based tools indicates that they can support a collaborative requirements process and in some cases support the creation of requirements documentations. However, none of them incorporate simulation as an elicitation technique to study the impact requirements will have on the organisational and associated IT infrastructure change. This research proposes to address the issue by incorporating this technique into a web-based collaborative requirement elicitation tool.

Rogers and Kincaid [21] convergence model describes communication as a dynamic process of idea and knowledge generation, which occurs over time through interaction with others and which leads to mutual understanding and collective action. The work of Lind and Zmud [3] shows that frequent communication helps create a mutual understanding of the role of IT infrastructure in supporting the business functions. Johnson and Lederer [2] extend this work to communication between the Chief Executive and Chief Information Officers. Their measures however are based on the subject's perception and they recommend that communication frequency would benefit from objective assessments. In addition, they mention that future research would benefit if they incorporate other dimensions to the frequency of communication such as the richness of the communication. The recommendation of using objective measures for frequency of communication and other dimensions that lead to a shared understanding form the basis of evaluating this research.

Requirements are often written in natural language (e.g., English) which is inherently ambiguous. This allows customers that are unfamiliar with modelling notations to still understand and validate requirement specifications [22]. A controlled natural language is a precisely defined subset of full English that can be used for communicating the organisations requirements in such a way that it can be automatically reasoned over by machines and thus removes the ambiguity issues of natural language. Attempto Controlled English (ACE) [23] demonstrates how a controlled natural language describes knowledge for the semantic web. This allows the language to be understandable by people and machines. A predictive editor [24] guides the stakeholders, word-by-word in the construction of a sentence that complies with ACE. The sentence can be converted to an ontological format using the ACE Parsing Engine (APE) [25]. The approach described with ACE shows the potential for a natural language interfaces to utilize semantic inference to refine and hone requirements which form part of the controlled natural language interface in CRESUS.

Simulation models play an important and inexpensive role in displaying significant features and characteristics of dynamic system, which one wishes to study, predict, modify, or control [8]. The true potential of simulation is in portraying the envisaged impact of certain decisions and changes on an operational system or process. Chandrasekaran et al [9] examines the synergy between web service technology and simulation. One of the approaches they propose is the creation of 
simulation models or components from web services in order to provide a high fidelity between the simulation and real world. It provides an ability to plug real web services into simulated entities, thus creating simulations that utilise as much 'real world' data as possible. The proposed approach of creating a simulation model from web services forms the basis of the simulation platform that represents the evolution of the IT infrastructure in CRESUS.

In summary, the communication of requirements is recognised as a critical activity to reaching a shared understanding between stakeholders involved in software development. Effective communication has been difficult to achieve and is a recurring problem in the elicitation of requirements. An increased amount of communication effort is often required to overcome the gap in communicating the requirements desired in a semantically consistent and understandable manner and then reflecting the potential impact of those requirements on the IT infrastructure.

The literature review demonstrates the potential for controlled natural language interfaces to utilise semantic inference to collaboratively communicate organisational requirements. A simulation represented by web services provides the stakeholders with the means to effectively communicate the potential impact of the requirements on the IT infrastructure. Thus, the use of a simulation model comprised of semantically enabled web services could potentially represent the evolution of the organisation's IT infrastructure. The literature also demonstrates the criteria for evaluating this research using objective measures for frequency of communication and other dimensions that lead to a shared understanding.

\section{OUTLINE OF RESEARCH}

\subsection{Research background}

This research explores to what extent CRESUS both aids communication in the development of a shared understanding and supports collaborative requirements elicitation to bring about organisational, and associated IT infrastructural, change. In addition, the experiment controls for title, role, level of service, and academic qualifications of employees at the National College of Ireland.

The experiment employed a pre-test-post-test control group design with matching participants in the experimental and control groups to evaluate the frequency of communication, quality of communication, participant's identification of organisational change issues, participant perceptions of attaining a shared representation of the IT infrastructure supporting organisational change, and, control variables that relate to title, role, level of service and academic qualifications.

In this context CRESUS is generally defined as a collaborative communication tool that allows stakeholders to communicate requirements from an ontological domain model, validate the requirements, and create a simulation of the IT infrastructure that supports those requirements. Communication will encompass three dimensions namely, frequency of communication, quality of communication and the identification of organisational change issues. Shared understanding is generally defined as the stakeholders' perception that the requirements represent the organisational and associated IT infrastructural change.

Organisational and associated IT infrastructural change will be generally defined as a series of IT systems denoted by web services that are semantically enabled and may access ontological data that represents the organisational changes as denoted by the stakeholders' requirements. 


\subsection{Method}

The following steps were carried out in developing CRESUS namely a literature review, evaluation of a scenario-based prototype, implementation of CRESUS and evaluation of CRESUS.

The literature review focused on organisational communication using a controlled natural language, shared understanding of organisational and associated IT infrastructural changes, collaborative requirements elicitation to bring about organisational and associated IT infrastructure change, and simulation that comprises of semantically enabled web services representing the evolution of the organisational IT infrastructure.

The evaluation of a scenario-based prototype is described in section 1. The implementation of CRESUS is described in section 4. Finally, the evaluation is described in section 5.

\section{ARCHITECTURE AND IMPLEMENTATION}

The architecture for the CRESUS tool was built around a controlled natural language interface, ontological domain model and a language translator that creates a simulation platform consisting of web services representing the evolution of the IT infrastructure as shown in Figure 1.

The architecture revolves around collaborative requirements elicitation between the business executive, IT architect and other stakeholders using controlled natural language. The language is guided by a lexicon that consists of nouns, proper nouns and verbs from the ontological domain model. The Knowledge Engineer creates an ontological domain model based on concepts, relationships and actual data from the problem domain.

The business executive, IT architect and stakeholders may create or modify requirements through the controlled natural language interface [24] as shown in Figure 2. These requirements are parsed to ensure that the grammar is based on a subset of natural language, namely Attempto Controlled English (ACE) [23] and stored in the ontological domain model. This results in machine accessible semantics that are automatically process-able. The controlled natural language interface component represents the only 3rd party component in this architecture.

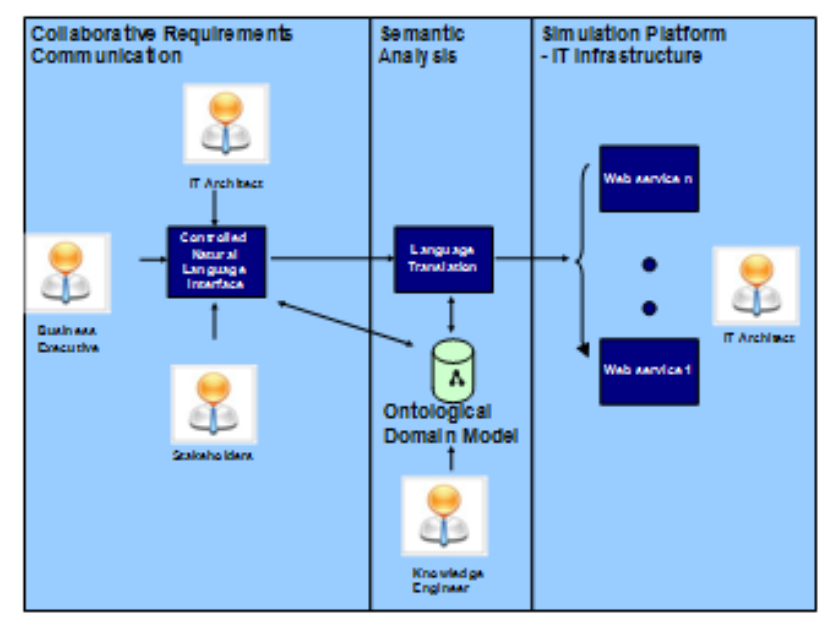

Figure 1. Architecture of CRESUS 


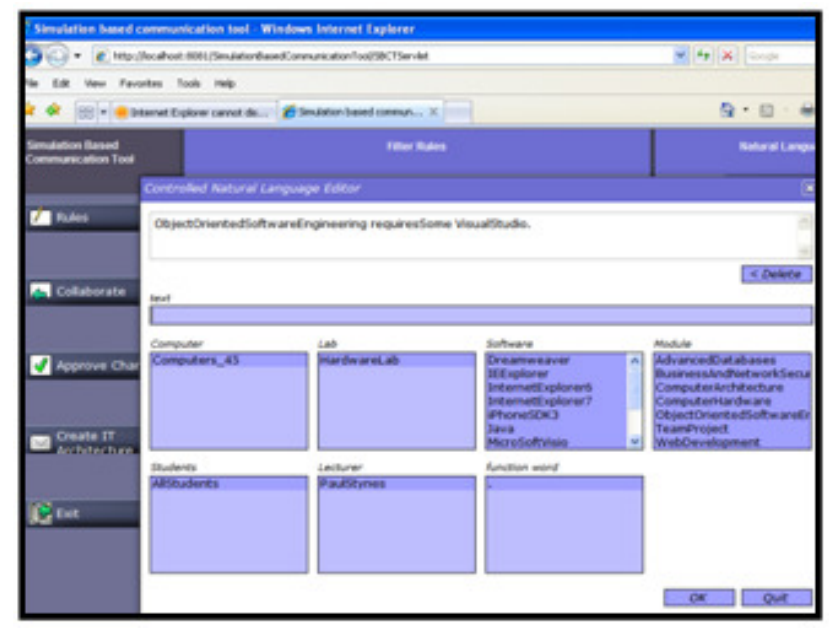

Figure 2. CRESUS - Controlled natural language interface (Preditor)

The language translator component parses the ontological domain model and applies a template rule to create the web services and simulation data.

Deployment of the web services results in the creation of the simulation platform that represents the evolution of the IT infrastructure. Staff can retrieve, create, delete and modify simulation data through the web service interfaces.

The innovation with CRESUS lies in the collaboration between the business executive, IT architect and stakeholders in creating a shared understanding of the evolving IT infrastructure that supports the requirements through the creation of semantically enabled web services and data structures during the simulation. The advantage of this approach is the high fidelity between the simulation and real world. It provides an ability to plug real web services into simulated entities, thus creating simulations that utilise as much empirical data as possible.

CRESUS is a web based application that is implemented in Java using the echo web framework [26]. The web based application is hosted on port 8081. Preditor [24] is a 3rd party product for the controlled natural language interface and is written in Java based on the echo web framework. The grammar that guides the controlled natural language interface is created using the Document Object Model (DOM) [27], The Attempto Controlled English Parsing Engine (APE) [25] server is a 3rd party product that is responsible for parsing the requirements from the business executive, IT architect and other stakeholders to ensure that they are a subset of ACE. In addition, APE converts the natural language to the Resource Description Framework (RDF) [28]. APE is set-up on port 8000. The ontological domain model is created using protégé [29]. The server side implementation uses Jena [30] which is a Java framework for building semantic web applications with RDF and the OWL Web Ontology Language [31]. The ontological domain model is incorporated into Jena. Jena uses Pellet [32] to reason over the ontological domain model. The server side implementation is also responsible for creating the simulation platform using the Java XML API and XSLT. XSLT is used for the language translation from the ontology domain model to the web services. The web services representing the simulation platform are implemented in Java and deployed on port 8083. Data for the web based application and the simulation platform is stored in an XML database, eXist [33] on port 8080. Interaction with the database involves the technologies XQuery, XUpdate and XPath. 


\section{EVALUATION}

\subsection{Background}

A member of the IT department at the National College of Ireland was interviewed about the process for creating the software environment in the computer laboratories. This process involves gathering software and hardware requirements for each module from lecturers. Then creating and testing an image of the software environment. And finally rolling the image out to all the pc's in the computer laboratories. Several issues that arose related to getting the module requirements in a timely fashion and confusion over changes to the software requirements of modules. This confusion related to requests for different software versions. There was an indication that the current process may improve by modifying the IT infrastructure for identifying the software and hardware requirements of each module. The results of the interview formed the basis of the scenario that was given to the control and experimental groups.

\subsection{Population}

Twelve employees of the National College of Ireland took part in the experiment. Eight of the employees were academics and three were from the IT department. The academics consisted of four course directors (lecturer grade II), one lecturer grade I, one fulltime lecturer grade II from the school of business, one postdoctoral research fellow and one support tutor. All academics lectured in the school of computing. The IT personnel consisted of one senior IT administrator, one IT support specialist and two IT support personnel.

\subsection{Operationalisation of variables}

In this context, communication is operationalised by the frequency of communication, quality of communication, and the identification of organisational change issues. Frequency of communication indicates the degree to which messages and responses take place between the business executive, IT architect, and staff. Quality of communication indicates the degree to which messages that identify organisational changes are successfully approved by the appropriate authority. Organisational change issues indicate the degree to which messages that identify organisational change issues are discovered but there is no progress to resolve those issues by the participants.

Shared understanding indicates the degree to which the business executive, staff and IT architect perceive that the IT infrastructure supports the organisational change faithfully.

\subsection{Methodology}

Data was captured through online questionnaires, a workshop, logs, observations and a debriefing session. The level of service and qualification's online questionnaire is a pre-test that contains nine items in three major content sections. The content sections are demographic details, service details and qualification details. The majority of these questions asked for factual information such as the person's title, role and work experience in the organisation. Other questions contain selection buttons such as gender, age and the number of years' service with NCI. The control information that relates to the title, role, level of service and academic qualifications used in the analysis for matching participants is derived from this questionnaire's data. Thereafter one employee of each match pair is randomly assigned to the experimental group and the other to the control group. The workshop involves a brainstorming session with each group that involves creating a conceptual model of the problem domain which is converted into an ontological domain model. The ontological domain model is used to constrain the words in the controlled 
natural language interface and the naming conventions for the automatically generated web services. The matching participants experiment involves exposing all groups to email as the communication tool and exposing the experimental group to an additional treatment of communication through CRESUS. The experiment is biased towards the use of asynchronous communication where the control group use only one tool i.e. email and the experimental group use two tools i.e., email and CRESUS. During the experiment, a log of all messages is stored in a communal email for each group and in addition the CRESUS logs each message. The information that relates to the frequency and quality of communication, and organisational change issues used in the analysis is derived from the log's data. Observations are noted on an A4 writing pad. The asynchronous communication for decision making online questionnaire is a post-test that contains thirteen items in four major content sections. The content sections are demographics, frequency of communication, quality of communication and perception. The majority of these questions asked for factual information such as the person's name, list any positive aspects of the experiment, list any negative aspects of the experiment, and list any suggested improvements to the experiment. Another question on participant's perception is based on a 1-5 semantic differential scale from "strongly disagree" to "strongly agree". The information that relates to the participant's perception of attaining a shared representation of the IT infrastructure supporting organisational change, used in the analysis is derived from this questionnaire's data. The online questionnaire was chosen as a data collection procedure for the study because of the rapid turnaround in data collection and the proficiency of participants with technology. The experimental group are administered the simulation based communication tool online survey. The survey contains thirtysix items. It was created specifically for this research by this author and contains items from several instruments [34-36]. The major content sections of this survey are demographic details, perceived usefulness, usability heuristics, user interface satisfaction, screen layout, learning and project specific questions. The perceived usefulness identifies details on frequency and quality of communication, shared understanding of how IT can support organisational changes, and if the web service simulation of the IT architecture supports the organisational change faithfully. The project specific questions identify details on how understandable the scenario is and if components of the simulation-based communication tool are understandable. The final step involves a debriefing of the results and validation by the participants. The results are analysed based on a paired samples t-test using SPSS.

\subsection{Results and data analysis}

The eight academics and four IT personnel that took part in the experiment completed the pre-test questionnaire with results described in Table 1. The table describes the participants' role, title, number of years of service with the National College of Ireland and their level of educational qualification attained based on the National Qualification Framework. Academic's 2, 3, 5 and 8 with a title of lecturer grade II and where their role indicates that they are programme directors are assigned the role of business executive. The academics 7, 11, 10 and 12 whose titles are lecturer grade I, lecturer grade II from the school of business, postdoctoral research fellow and support tutor, and where their role indicates that they lecture in the school of computing are assigned to the role of staff. The IT personnel 1, 4, 6 and 9 with the titles senior IT administrator, one IT support specialist and two IT support personnel are assigned the role of IT architect. The academics and IT personnel are pair matched based on their number of years of service with the National College of Ireland and their level of educational qualification attained based on the national qualification framework. The matched participants are 2 and 3; 7 and 11;4 and 6;5 and $8 ; 10$ and 12; and finally 1 and 9. Participants were randomly allocated to the experimental and control groups as follows, participants 2, 7 and 1 to experimental group one; participants 3, 11 and 9 to control group two; participants 8,10 and 4 to experimental group three; and participants 5,12 and 6 to control group four. 
Table 1. Matching participants based on level of service and academic qualification

\begin{tabular}{|c|c|c|c|c|c|c|c|c|c|c|c|}
\hline \multirow[t]{2}{*}{ Role } & \multirow[t]{2}{*}{ Name } & \multirow[t]{2}{*}{ Title } & \multicolumn{6}{|c|}{ Number of years of service with $\mathrm{NCl}$} & \multicolumn{3}{|c|}{$\begin{array}{l}\text { The level of education attained } \\
\text { based on the National } \\
\text { Qualification Framework }\end{array}$} \\
\hline & & & 1-2 years & $3-4$ years & $5-6$ years & 7-8 years & $9-10$ years & $>10$ years & \begin{tabular}{|l|} 
Honours \\
Degree
\end{tabular} & Masters & $\mathrm{PhD}$ \\
\hline \multirow{4}{*}{$\begin{array}{l}\text { Programme } \\
\text { Director }\end{array}$} & & 2 Lecturer II & & & & $\mathrm{x}$ & & & & $x$ & \\
\hline & & 3 Lecturer II & & & & $x$ & & & & $\mathrm{x}$ & \\
\hline & & Lecturer II & & & $\mathrm{x}$ & & & & & & $x$ \\
\hline & & Lecturer II & & & & & $x$ & & to & $x$ & \\
\hline \multirow{4}{*}{$\begin{array}{l}\text { Lecture in } \\
\text { School of } \\
\text { Computing }\end{array}$} & & Lecturer I & $x$ & & & & & & $x$ & 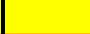 & \\
\hline & 10 & $\begin{array}{l}\text { Computing } \\
\text { Support } \\
\text { Tutor }\end{array}$ & $x$ & & & & & & & $\mathrm{X}$ & \\
\hline & 11 & $\begin{array}{l}\text { Post- } \\
\text { Doctoral } \\
\text { Research } \\
\text { Fellow }\end{array}$ & $\mathrm{x}$ & & & & & & $\mathrm{X}$ & & \\
\hline & 12 & Lecturer II & & & & & & $x$ & & $x$ & \\
\hline \multirow[t]{4}{*}{ IT personnel } & & $\begin{array}{l}\text { Senior IT } \\
\text { Administrator }\end{array}$ & & & & $x$ & & & & $\mathrm{x}$ & \\
\hline & & IT support & & $x$ & & & & & $x$ & & \\
\hline & 6 & IT support & & $x$ & & & & & $x$ & & \\
\hline & & $\begin{array}{l}\text { IT Support } \\
\text { Specialist }\end{array}$ & & & & $\mathrm{x}$ & & & $\mathrm{x}$ & & \\
\hline
\end{tabular}

\begin{tabular}{|l|l|}
\hline Legend & \\
\hline & Experimental group 1 \\
\hline & Control group 2 \\
\hline & Experimental group 3 \\
\hline & Control group 4 \\
\hline
\end{tabular}

The results from the brainstorming session define the problem domain model and the approval process for any requirements that will be identified. The problem domain model is converted into an ontology domain model which is used to constrain the grammar in the controlled natural language interface and the naming conventions in the automatically generated web services. A sample of the conceptual model and approval process that one of the group's identified, related to the concepts of Module and Software. An example of a rule was "Module requires Software" with instance data that represents an organisational change such as "Software Development requires Netbeans". In one group the approval process was for the executive to approve any requirements that the staff identifies. If approval is granted, then the rule goes to the IT architect for further approval before becoming part of the ontological domain model.

The results from CRESUS logs and the email tool are displayed from Figure 3 to Figure 5. A comparative analysis of the data from Figure 3 indicates that the frequency of communication is significantly higher with the experimental group than the control group, where the experimental group use the CRESUS tool and email to communicate. The control group uses only email.

Figure 4 indicates that there are no significant differences in the quality of communication between the experimental and control groups. However, a deeper analysis of the results clearly shows that staff in the experimental groups (participants 7 and 10) identifies the majority of organisational changes that are successfully approved by the appropriate authority compared to the control groups. This result may be worth further exploration through additional experiments. Another observation was that in general the IT architect did not contribute to defining the organisational changes. This is as expected as the IT architect is responsible for identifying the IT infrastructure that provides support to the organisational change rather than forcing the organisational change in any particular direction. There was one exception to this observation in 
the fourth control group where the IT architect identifies one organisational change. The result in this instance is biased as the IT architect is actually part of the real process for rolling out the IT environment to the pc's and had knowledge that the other IT architects did not have.

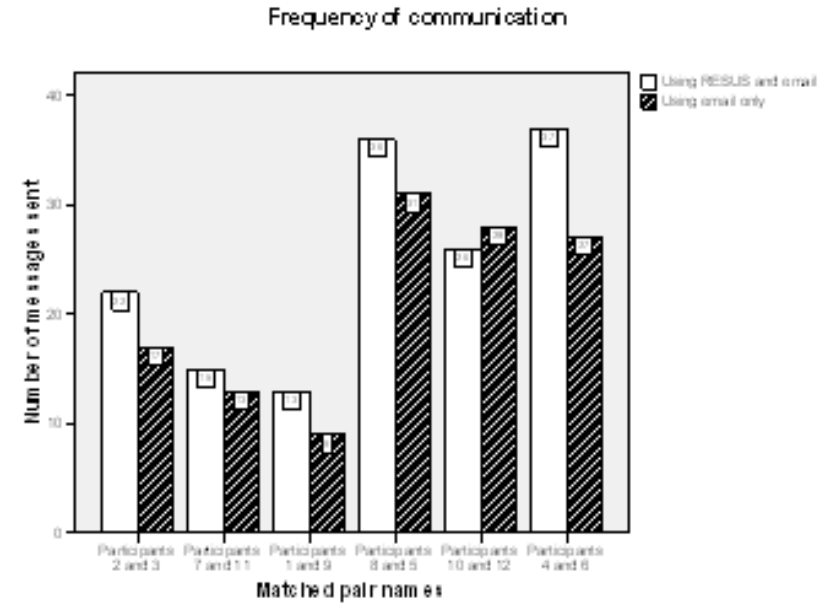

Figure 3. Frequency of communication

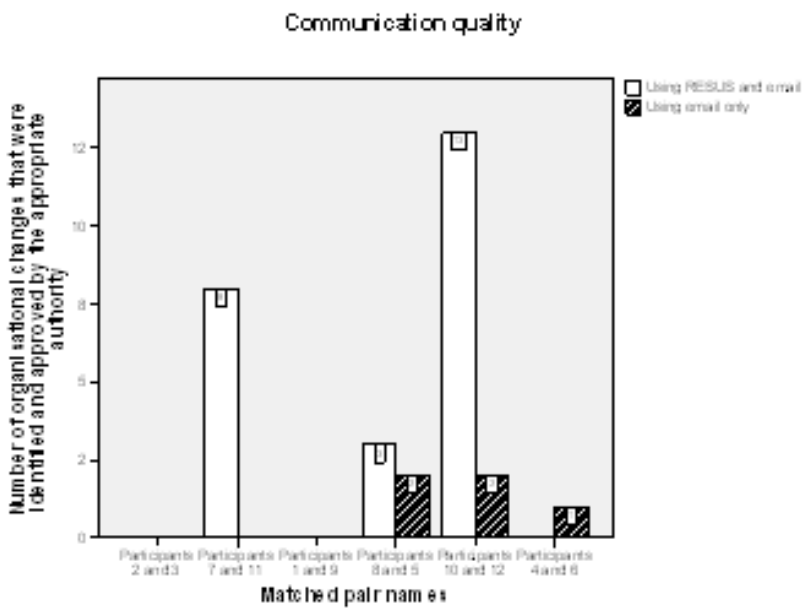

Figure 4. Communication Quality

The comparison in Figure 5 indicates that the identification of organisational change issues is significantly higher among participants in the control group that use email only, compared to the experimental group. Though initially unexpected, upon reflection the control group's communication was not constrained by identifying organisational changes only, and so the control group's communication was wider in scope which led to the identification of more issues. Other results from the post-test online questionnaire indicate there is no difference between the experimental and control groups for the participant's perception of attaining a shared representation of the IT infrastructure supporting organisational change. On reflection one of the goals of all four groups was to identify an IT system that could support the organisational changes. As the operational metric was based on perception then it stands to reason that there will be no difference between the groups in identifying the IT infrastructure that supports the organisational changes. The qualitative feedback from the experimental groups indicates that CRESUS facilitates collaboration and communication around the IT architecture with comments such as "Very useful tool for defining requirements and collaboration" and "Provided a new means for communication around IT infrastructure". 


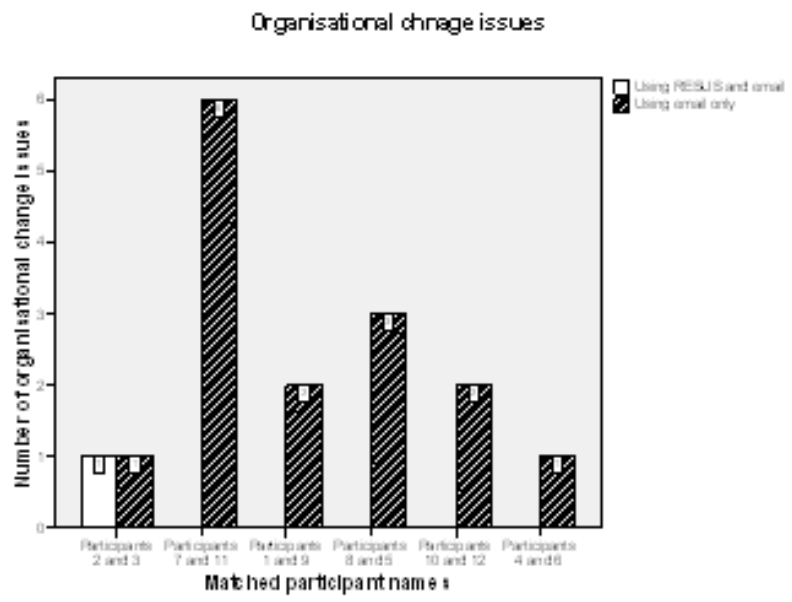

Figure 5. Organisational change issues

The design of CRESUS ensures that participants focus the communication on identifying requirements that relate to the organisational changes and approving those changes. Followed by, an automatic creation of the IT architecture to support those changes. This was as observed with the experimental group's one and three. An observation of control group two by the experimenter and validated by the group indicates that they spent a substantial amount of work defining the IT infrastructure. This group had two suggested solutions, but had not made a decision on which solution to adopt. One of the participants of that group made the following comment "Maybe the contributed should be told not to focus on specific technologies too much". This comment highlights an advantage of using CRESUS in that it allows the participants to focus on communicating about the business and not the technology.

\section{LIMITATIONS}

This was the first experiment with the tool and so it was important to get early feedback and direction on further development and experimentation. As such the experiment took place at the National College of Ireland. One of the goals of the experiment was to demonstrate that the architecture has the possibility to scale up to the full expressivity of the controlled natural language and so for this experiment sentences were constrained to simple "noun verb noun".

Maturation was seen as a threat to the matched participants' research design used in this experiment. Maturation is where participants mature or change during the experiment. The experimenter attempted to select participants that would mature at the same rate. In group one and group two, participant 2 and participant 3 are both studying for a $\mathrm{PhD}$. During the experiment, participant 2 completed the viva. Also in group one and group two, participant 7 and participant 11 both currently have an honours degree and are both completing a PhD. During the course of the experiment, participant 11 completed a viva. Survey items that capture potential maturation should be incorporated into a pre-test.

Metrics used for the participants' perception of attaining a shared representation of the IT systems that supports the organisational change were not suitable for a matching participant's research design. As each group is communicating collaboratively to make decisions about organisational changes and creating the IT system that supports those changes. Thus it stands to reason that there will be no significant differences in perception. Objective metrics instead of participants' perceptions should be used in further experimentation. 
In group four, participant 6 is involved with the roll out of the IT environment and this extra knowledge would have biased the results in particular when identifying an IT system and identifying organisational change solutions, issues and constraints. Survey items that capture the participants' role in relation to the scenario should be incorporated into a pre-test and controlled for in future experiments.

A weakness in the experimental design was that the controlled experiment was conducted in a one hour setting which would not be representative of actual communication behaviours among the employees. Further experimentation should be conducted over a longer period of time and incorporated into their actual job so that it is representative of their actual communication patterns. The limitations will be addressed in further experimentation.

\section{CONCLUSION}

The goal of requirements elicitation is to reach a shared understanding between all parties involved in the communication process which often involves an increased amount of communication effort to overcome the gap in communicating the requirements desired in a semantically consistent and understandable manner and then reflecting the potential impact of those requirements on the IT infrastructure.

An initial study conducted among ten business executives in higher education indicates a desire by the majority of this small group for a tool that allows them to communicate organisational changes using natural language where these changes are automatically translated into the IT infrastructure that supports a business process.

Building on this research, CRESUS was implemented as a collaborative communication tool that allows stakeholders to communicate requirements from an ontological domain model, validate the requirements, and create a simulation of the IT infrastructure that supports those requirements. The tool was evaluated at the National College of Ireland.

Results show that the tool significantly increases the frequency of communication which is a predictor of reaching a shared understanding between all stakeholders during requirements elicitation. In addition, evidence from the experiment suggests that the tool increases the quality of communication initiated by staff. Qualitative feedback from participants that use CRESUS indicates that the tool facilitates collaboration and communication around the IT architecture with comments such as "good for storing knowledge and facilitating collaboration" and "Provided a new means for communication around the IT infrastructure".

In conclusion CRESUS shows promise as a tool for collaborative requirements elicitation through increased communication and understanding around organisational and IT infrastructural change.

\section{FUTURE WORK}

Web services can be orchestrated into an executable business process using the business process execution language. As such future work will involve investigating CRESUS's role in collaborative requirements elicitation for the creation of the IT infrastructure that supports a business process.

Further evaluation is required to investigate the significance of the quality of communication among staff, objective metrics for attaining a shared understanding of the IT infrastructure that supports the organisational change with the provision that the metrics are objective and not based on the participant's perception. The experiment will be conducted in different organisations over 
a longer period of time such that it replicates their actual communication patterns. Questionnaire items that capture maturation and participants' role that relates to the organisational change scenario will be included in the pre-test.

\section{REFERENCES}

[1] Preston, D. S., Karahanna, E., \& Rowe, F. (2006). Development of shared understanding between the chief information officer and top management team in U.S. and French Organizations: A crosscultural comparison. IEEE Transactions on Engineering Management, 53(2), 191-206. doi: 10.1109/TEM.2006.872244.

[2] Johnson, A.M., \& Lederer, A.L., (2005). The effect of communication frequency and channel richness on the convergence between chief executive and chief information officers. Journal of Management Information Systems / Fall 2005, Vol. 22, No. 2, pp. 227-252.

[3] Lind, M. R., \& Zmud, R. W. (1991). The Influence of a Convergence in Understanding between Technology Providers and Users on Information Technology Innovativeness. Organization Science, 2(2), pp. 195-217.

[4] Sommerville I., Software Engineering, 6h Edition, Addison-Wesley,Harlow, England. 2001.

[5] Gilvaz A. P.,and J. C. S.P. Leite, .FAES : A Case Tool for Information Acquisition., Case .95, Proceedings of the Seventh Intl. Work on Computer Aided Software engineering. IEEE Computer Society Press, July 1995, pp. 260-269.

[6] Christel, Micheal G, et al. (1993).AMORE: The Advanced Multimedia Organizer for Requirements Elicitation., Technical Report CMU/SEI-93-TR-12.

[7] Sawyer P., Sommerville, I., and Viller, S. (1996). PREview: Tackling the Real Concerns of Requirements Engineering., CSEG Technical Report, Computing Department, Lancaster University.

[8] Kellner, Madachy, and Raffo, (1999), "Software Process Modeling and Simulation: Why, What, How," Journal of Systems and Software, Vol. 46, No. 2/3.

[9] Chandrasekaran, S., Silver, G., Miller, J., Cardoso, J. \& Sheth, A. (2002) XML-based modeling and simulation: Web service technologies and their synergy with simulation. IN: Proceedings of the 34th Winter Simulation Conference: exploring new frontiers (WSC 2002), 8-11, December, San Diego, California, USA. Winter Simulation Conference. pp 606-615.

[10] Stynes, P., Conlan, O., O’Sullivan, D. (2008) Towards a Simulation-based Communication Tool to Support Semantic Business Process Management. IN: Proceedings of the Fourth International Workshop on Semantic Business Process Management in Proceedings of Workshops held at the Fifth European Semantic Web Conference, (ESWC08), 2nd June, Tenerife, Canary Islands, Spain.

[11] Gottesdeiner, E., Requirements by Collaboration, Addison-Wesley, 2002.

[12] Bostrum, R.P. (1989). Successful application of communication techniques to improve the systems development process. Inform Manage 1989; 16: 279-295.

[13] Saiedian H, Dale R. Requirements engineering: making the connection between the software developer and the customer. Inform Software Tech 2000; 42 (6): 419-428.

[14] Macaulay LA. Requirements Engineering. Springer-Verlag, London, 1996.

[15] Christel MG, Kang KC. (1992). Issues in requirements elicitation. Technical Report CMU/SEI-92TR-12 ESC-TR-92-012. 
[16] Coughlan, J., \& Macredie, R. D. (2002). Effective communication in requirements elicitation: A comparison of methodologies. Requirements Engineering, 7(2), 47-60.

[17] Marakas, G.M., Elam, J.J., (1998). Semantic structuring in analyst and representation of facts in requirements analysis. Inform Syst Research; 9 (1): 37-63.

[18] VordTool, available at URL http://www.filewatcher.com/b/ftp/ftp.gmu.edu/drine/cs_se2/CourseMaterials/SupplementaryProjectM aterials/Supplements_TextBookChapter7_Technology-0.html.

[19] TeamWave Software Ltd., Availabale at URL http://www.teamwave.com/, 2001.

[20] Hassan, S., \& Salim, S. S. (2004). A Tool to Support Collaborative Requirements Elicitation using Viewpoint Approach'. In 1st International Conference on Informatics, Izmir, Turkey, September 2004, (pp. 1-4).

[21] Rogers, E.M., and Kincaid, D.L. Communication Networks. New York: Free Press, 1981.

[22] Institute of Electrical and Electronic Engineers, (1998), IEEE Recommended Practice for Software Requirements Specifications. IEEE Standard 830-1998, Institute of Electrical and Electronic Engineers, New York.

[23] Norbert E. Fuchs, Kaarel Kaljurand, and Tobias Kuhn. (2008). Attempto Controlled English for Knowledge Representation. In Cristina Baroglio, Piero A. Bonatti, Jan Maluszynski, Massimo Marchiori, Axel Polleres, and Sebastian Schaffert, editors, Reasoning Web, Fourth International Summer School 2008, number 5224 in Lecture Notes in Computer Science, pages 104-124. Springer.

[24] Kuhn, T., (2008). Combining Semantic Wikis and Controlled Natural Language. Proceedings of the Poster and Demonstration Session at the 7th International Semantic Web Conference (ISWC2008), CEUR Workshop Proceedings, 2008.

[25] Kaarel Kaljurand and Norbert E. Fuchs. (2006) Bidirectional mapping between OWL DL and Attempto Controlled English. In Fourth Workshop on Principles and Practice of Semantic Web Reasoning, Budva, Montenegro.

[26] Echo2 Web framework Available from http://echo.nextapp.com/site/ [last accessed on 11th February, 2010.

[27] Document Object Model (DOM). Available from http://www.w3.org/DOM/ [last accessed on 11th February, 2010]

[28] Resource Description Framework (RDF). Available from http://www.w3.org/RDF/ [last accessed on 11th February, 2010]

[29] Protégé. Available from http://protege.stanford.edu/ [last accessed on 11th February, 2010]

[30] Jena - A semantic web framework for Java. Available from http://jena.sourceforge.net/ [last accessed on 11th February, 2010]

[31] OWL Web Ontology Language. Available from http://www.w3.org/TR/owl-features/ [last accessed on 11th February, 2010]

[32] Pellet: OWL 2 Reasoner for Java. Available from http://clarkparsia.com/pellet [last accessed on 11th February, 2010]

[33] XML Database, eXist. Available from http://exist.sourceforge.net/ [last accessed on 11th February, 2010] 
[34] Nielsen, J. (1993) Usability Engineering. Academic Press. Chapter 5, p. 115. http://hcibib.org/perlman/question.cgi?form=NHE

[35] Chin, J.P., Diehl, V.A., Norman, K.L. (1988) Development of an Instrument Measuring User Satisfaction of the Human-Computer Interface. ACM CHI'88 Proceedings, 213-218. ()1988 ACM. http://hcibib.org/perlman/question.cgi?form=QUIS.

[36] Davis, F. D. (1989) Perceived Usefulness, Perceived Ease of Use, and User Acceptance of Information Technolog. http://hcibib.org/perlman/question.cgi?form=PUEU

\section{AUTHORS}

\section{Dr Paul Stynes}

Dr Paul Stynes is Vice Dean of Academic Programmes and Research at the National College of Ireland. He completed a PhD in 2015 at Trinity College Dublin. His research interests are in the area of Collaborative requirements elicitation and Intelligent Systems specifically semantic web, and ontologies.

\section{Prof. Owen Conlan}

Prof. Conlan is an internationally recognised research leader in User Modelling, Adaptation, Personalisation and Visualisation research with over 160 publications in those fields. Owen is a Fellow of Trinity College Dublin and leads the Personalisation research in the ADAPT Centre (www.adaptcentre.ie).

\section{Prof. Declan O’Sullivan}

Prof. Declan O'Sullivan is Director of Research and Head of Discipline for Intelligent Systems at Trinity College Dublin. Declan was awarded a B.A. (Mod) in Computer Science from TCD in 1985, an M.Sc. in Computer Science from TCD in 1988, and a Ph.D. in Computer Science from TCD in 2006. Declan has substantial research experience in academia and industry, having worked for IONA Technologies and Broadcom Eireann Research.
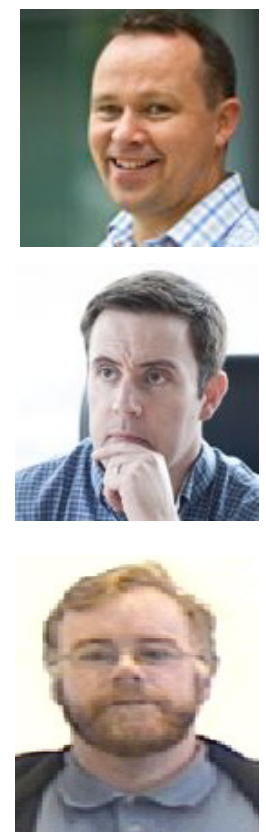